\title{
The Optimization of Ozonolysis Reaction For Synthesis of Biopolyol From Used Palm Gooking Oil
}

\section{Edy Purwanto *,1}

Lieke Riadi ${ }^{1,2}$

Nathania Tamara I. $^{1}$

Mellisha Ika K. ${ }^{1}$

1 Chemical Engineering Department, University of Surabaya, Raya Kalirungkut 60293, Surabaya, East Java, Indonesia

${ }^{2}$ Center for Environmental Studies, University of Surabaya, Raya Kalirungkut 60293, Surabaya, East Java, Indonesia

`e-mail : edypurwanto@staff.ubaya.ac.id

Biopolyol is a raw material for synthesis of polyurethanes which is used as thermoset and thermoplastic materials, adhesives, rigid or non-rigid foams and also for coating. The utilization of waste edible oil as feedstock for synthesis of biopolyol has attracted some researchers. However, there is little attention focused on the application of ozone technology for synthesis of biopolyol from used cooking oil through ozonolysis reaction. Response surface methodology was performed to determine the optimal operating condition in the synthesis of biopolyol using ozone and sorbitol as a hydroxyl group source. The influence of input variables such as temperature, reaction time, molar ratio of oil to sorbitol and ozone concentration on hydroxyl value quantified was studied. The optimal condition was determined by high amount of hydroxyl value resulted from response surface method which used the experimental data. The ozonolysis reaction was conducted in a batch reactor equipped with agitator, tube sparger, thermocouple, reflux condenser and potassium iodide trap. Central composite design with four independent variables and one response variable was performed to determine the influence of independent variables on output variable of hydroxyl value of biopolyol. The hydroxyl value of polyol is a quadratic function of molar ratio of oil to methanol and a linear function of reaction temperature. The optimal operating condition was achieved at a temperature of $250 \mathrm{C}$, a reaction time of 5 hours, molar ratio of used cooking oil to sorbitol is $1: 7$ and ozone concentration about $4.8 \%$.

Keywords: Ozonolysis; Biopolyol; Hydroxyl value; Used cooking oil; Palm oil

\section{INTRODUCTION}

Polyurethanes usually derived from petroleum have many applications such as for thermoset and thermoplastics materials, coatings, rigid and non-rigid foams and adhesives (Lligadas et al., 2006; Wang et al., 2009). Therefore, the demand of polyol is estimated increase each year whereas the amount of petroleum as a 
main raw material for synthesis of polyol is turning down. Polyurethanes are basically synthesized from the reaction between polyols and diisocyanate (Pechar et al., 2006). Polyol is derived from petroleum which is known as non-renewable resource, therefore effort is needed to find out an alternative raw material and technology for polyol synthesis that can increase the economic value of waste and reduce the energy consumption for polyol production (Tu et al., 2007). Used palm cooking oil is an alternative feed stock for polyol synthesis and ozone is powerful gas to break the double bond in the unsaturated fatty acids content then enable hydroxyl group to produce biopolyol.

Basically, biopolyol can be produced through two consecutive reactions called epoxidation and hydroxylation reactions (Petrovic et al., 2003). In the epoxidation step, double bonds in the oil are converted to epoxidize oil where oxirane ring is produced. Then in the hydroxylation step, oxirane ring is converted to hydroxyl groups namely polyol. However, those methods epoxidation and hydroxylation reactions require high reaction temperature between $40-60^{\circ} \mathrm{C}$. Therefore ozone technology could overcome this problem because ozonolysis reaction needs lower temperature which is only at ambient temperature.

Used palm cooking oil has a high potential as biopolyol source in Indonesia. The local disposal of used frying oil becomes a huge problem due to the large volumes of waste involved. In the fastfood restaurant business, a single branch which serves fried foods such as fried chicken, french fries and burgers can produce as much as 15 liters of used cooking oil per day. Another reason is that used palm cooking oil provides high content of unsaturated fatty acid which is about 50\% w/w (oleic, linoleic and linolenic acid) indicated by iodine value in the range of $52-58 \mathrm{~g} \mathrm{I}_{2} / 100 \mathrm{~g}$ oil (Bailey 1951). High quality biopolyol is indicated by high hydroxyl value, which is related to high content of unsaturated fatty acids in the used palm oil, since the double bond in unsaturated fatty acids will be converted to hydroxyl group by ozonolysis which is presented as hydroxyl value.

The disposal of waste cooking oil has to be carried out carefully since it is regulated in some countries such as Animal ByProduct Regulation in May 2002 which does not allow catering premises to sell their used cooking oil to animal feed manufacturers. Consequently, the caterers tend to dispose their used cooking oil into the drain then results in the deterioration of water stream quality and choking the drainage system and aggregation of grease which cause smelly odor and some diseases. Current disposal of waste cooking oil as animal feed source may no longer be acceptable due to stringent prohibiting to be used as animal feed source. Therefore an alternative disposal method to handle this used cooking oil is by converting it to high added value products needs to be developed. Hence, the production of biopolyol as a raw material for synthesis of polyurethanes from waste edible oil needs to be promoted.

The key goal of this research is to study the influence on input variables (reaction 
temperature, reaction time, molar ratio of oil to sorbitol and ozone concentration) on the hydroxyl value of biopolyol products and to determine the optimal operating condition for synthesis of biopolyol through ozonolysis reaction from used palm cooking oil.

\section{MATERIALS AND METHODS}

\section{Materials}

Materials was used in this research are used palm cooking oil obtained from one of fast food restaurant in Surabaya. Sorbitol solution (purity of $70 \%$ ) and sulphuric acid (purity of 97\%) was purchased from Merck. Ozone was generated using ozone generator from oxygen gas (purity of 99.5\%) supplied by Aneka Gas Industri (AGI).

\section{Methods}

Prior to the ozonolysis reaction, used palm cooking oil was analyzed for its fatty acid content by Gas Chromatography. The experimental method for biopolyol synthesis (adapted from Baber et al. 2005) is as follows: A mixture of used palm cooking oil, sorbitol and sulphuric acid catalyst was added into a 1.5 liters stainless steel reactor $(H / D=1.5)$ equipped with cooling/heating system, stirrer, tube sparger and thermocouple. The molar ratio of used palm cooking oil to sorbitol was varied according to the experimental design. Ozone was produced from oxygen gas using ozone generator. The exit port of the ozone generator was connected with a deep tube and the ozone from ozone generator was delivered to the reactor through tube sparger at the bottom of the reactor. The reactor outlet was connected to a potassium iodide solution trap hence excess ozone will be decomposed to oxygen (See Figure 1).

The reaction was run at several isothermal conditions and certain reaction times. After ozonolysis reaction, the generator was turned off and the product of reaction was then flushed with oxygen gas for about 10 minutes to remove the ozone excess. Following this, the reaction product was allowed to attain ambient temperature and then neutralized using sodium carbonate solution. The mixture is then decanted into a separator funnel then warm water was added to separate biopolyol and sorbitol excess as water-

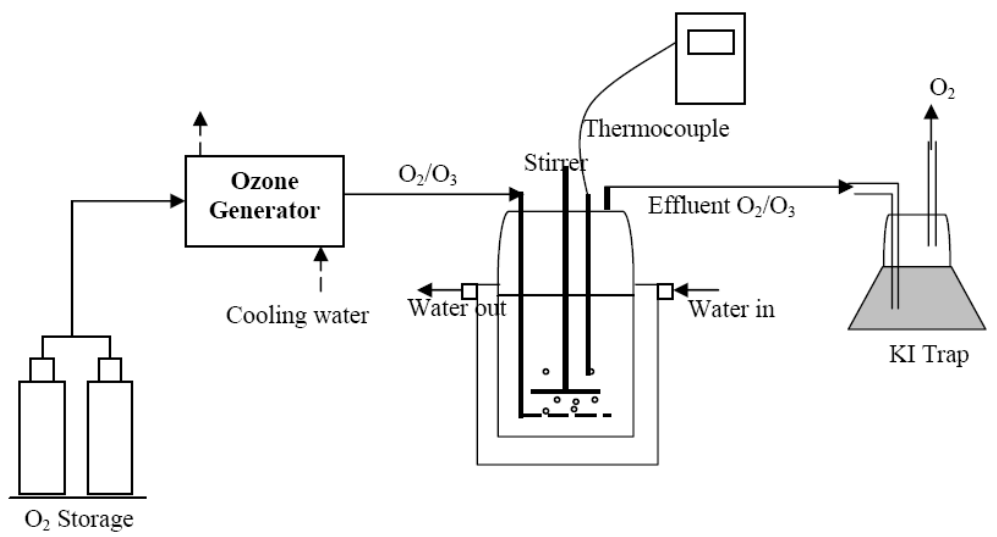

Fig. 1: Experimental Apparatus 
Table 1. Range and Level Variables

\begin{tabular}{lcccccc}
\hline \multirow{2}{*}{ Variables } & Coded & \multicolumn{4}{c}{ Range and level } \\
& value & -2 & -1 & 0 & 1 & 2 \\
\hline Temperature $\left({ }^{\circ} \mathrm{C}\right)$ & $X_{1}$ & 25 & 30 & 35 & 30 & 35 \\
Reaction time $(\mathrm{h})$ & $X_{2}$ & 1 & 2 & 3 & 4 & 5 \\
Molar ratio & $X_{3}$ & $1: 3$ & $1: 4$ & $1: 5$ & $1: 6$ & $1: 7$ \\
Cozone $_{\text {o }} \%$ mole $)$ & $X_{4}$ & 4.8 & 5.3 & 5.8 & 6.3 & 6.8 \\
\hline
\end{tabular}

soluble ones. Separated biopolyol was then washed with warm water to separate residual contaminants until washing water was neutral. The resulted product was then dried with magnesium sulfate anhydrous and then filtered. The biopolyol product was then analyzed for its hydroxyl value content using titration method. The formation of hydroxyl groups and the disappearance of double bonds was identified qualitatively by FTIR.

\section{Experimental Design}

Full factorial central composite design (CCD) was used to determine the total number of experiments applying the equation $2^{k}+2 k+n_{0}$ (Doddapaneni et al. 2007) where $2^{k}$ is factorial design, $2 k$ is star point, $k$ is total number of independent variables, and $n_{0}$ is total number of replication at central point.

This research focused on the effect of four independent variables reaction temperature $\left(X_{1}\right)$, reaction time $\left(X_{2}\right)$, molar ratio of oil to sorbitol $\left(X_{3}\right)$ and ozone concentration $\left(X_{4}\right)$ on response variable of hydroxyl value of polyol product $(Y)$. The central values of independent variables were: reaction temperature at $35^{\circ} \mathrm{C} ; 3$ hours reaction time, 1:5 molar ratio of oil to sorbitol; and ozone concentration of $5.8 \%$. Four independent variables were studied and optimized in the form of coded value $X_{1}, X_{2}, X_{3}$, and $X_{4}$ at five levels $(-2,-1,0,1,2)$ using Equation (1):

$$
X_{i}=\frac{x_{i}-x_{0}}{\Delta x_{i}}
$$

where $X_{i}$ is coded value of independent variable, $x_{i}$ is real value of independent variable, $x_{0}$ is real value of independent variable at central point, and $\Delta x_{i}$ is interval. The distribution of coded values $X_{1}, X_{2}, X_{3}$, and $X_{4}$ as described in Table 1.

\section{RESULTS AND DISCUSSIONS}

The characterization of used palm cooking oil using in this research is dark oily liquid with the density of $0.911 \mathrm{~g} / \mathrm{ml}$ and viscosity about $15.1 \mathrm{cP}$. The content of fatty acids in the oil based on Gas Chromatography analysis showed various fatty acids content as described in Table 2 .

Table 2. Fatty Acid Composition of Used Palm Cooking Oil

\begin{tabular}{cc}
\hline Saturated fatty acid & Composition (wt \%) \\
\hline Lauric acid & 0.11 \\
Myristic acid & 0.83 \\
Palmitic acid & 36.8 \\
Stearic acid & 3.50 \\
\hline Unsaturated fatty acid & Composition (wt \%) \\
\hline Oleic acid & 40.3 \\
Linoleic acid & 10.4 \\
\hline
\end{tabular}


Table 3.CCD and Response Variables

\begin{tabular}{cccccc}
\hline Run & $\begin{array}{c}\text { Temperature } \\
\left({ }^{\mathbf{C}} \mathbf{C}\right)\end{array}$ & $\begin{array}{c}\text { Reaction time } \\
(\boldsymbol{h})\end{array}$ & $\begin{array}{c}\text { Molar Ratio } \\
\text { (oil to sorbitol) }\end{array}$ & $\begin{array}{c}\mathbf{C}_{\text {ozone }} \\
\text { (\% mole) }\end{array}$ & $\begin{array}{c}\boldsymbol{Y} \\
\text { (mg } \mathbf{~ K O H / g ~ o i l ) ~}\end{array}$ \\
\hline 1 & 40 & 2 & $1: 4$ & 5.3 & 111.9 \\
2 & 30 & 2 & $1: 4$ & 5.3 & 133.1 \\
3 & 35 & 3 & $1: 5$ & 5.8 & 118.4 \\
4 & 40 & 2 & $1: 6$ & 5.3 & 117.1 \\
5 & 45 & 3 & $1: 5$ & 5.8 & 89.5 \\
6 & 35 & 3 & $1: 5$ & 4.8 & 115.5 \\
7 & 30 & 2 & $1: 6$ & 6.3 & 121.1 \\
8 & 35 & 1 & $1: 5$ & 5.8 & 113.5 \\
9 & 40 & 4 & $1: 6$ & 5.3 & 118.7 \\
10 & 30 & 2 & $1: 4$ & 6.3 & 134.5 \\
11 & 30 & 4 & $1: 4$ & 6.3 & 135.6 \\
12 & 35 & 3 & $1: 5$ & 5.8 & 118.6 \\
13 & 30 & 4 & $1: 4$ & 5.3 & 135.5 \\
14 & 35 & 3 & $1: 5$ & 5.8 & 117.3 \\
15 & 40 & 4 & $1: 4$ & 6.3 & 118.7 \\
16 & 35 & 3 & $1: 5$ & 5.8 & 117.3 \\
17 & 40 & 4 & $1: 6$ & 6.3 & 121.5 \\
18 & 25 & 3 & $1: 5$ & 5.8 & 134.5 \\
19 & 40 & 2 & $1: 4$ & 6.3 & 117.6 \\
20 & 35 & 5 & $1: 5$ & 5.8 & 124.9 \\
21 & 30 & 4 & $1: 6$ & 6.3 & 123.0 \\
22 & 35 & 3 & $1: 5$ & 5.8 & 117.7 \\
23 & 40 & 4 & $1: 4$ & 5.3 & 116.5 \\
24 & 35 & 3 & $1: 5$ & 6.8 & 117.5 \\
25 & 30 & 2 & $1: 6$ & 5.3 & 149.2 \\
26 & 35 & 3 & $1: 3$ & 5.8 & 131.8 \\
27 & 35 & 3 & $1: 5$ & 5.8 & 118.7 \\
28 & 30 & 4 & $1: 6$ & 5.3 & 153.1 \\
29 & 35 & 3 & $1: 7$ & 5.8 & 122.1 \\
30 & 40 & 2 & $1: 6$ & 6.3 & 118.7 \\
31 & 35 & 3 & $1: 5$ & 5.8 & 117.3 \\
\hline
\end{tabular}

Used palm cooking oil had high content of unsaturated fatty acid which was about 50.7 weight \% (oleic and linoleic acids). High content of unsaturated fatty acid is needed for the conversion of double bonds to polyol as ozone only attack double bonds in the oil.

Response Surface Methodology (RSM) is very effective method to study the influence of independent variables on response variables therefore the optimum condition could be determined (Montgomery, 2005). Furthermore, the interaction between process variables could be determined using RSM (Wang et al., 2008), it will save time as a number of experiments can be reduced (Doddapaneni et al., 2007).

\section{Statistical Analysis}

A second order polynomial model was fitted to represent the experimental data presented in Table 3 using the Equation (2) as in the second order polynomial model consist of linear, quadratic functions, and also the interaction of input variables: 
Table 4. Significance of Regression Coefficients for $Y$

\begin{tabular}{ccccc}
\hline & Coefficients & Standard error & t Statistic & p-value \\
\hline Intercept & 117.900 & 2.515 & 46.887 & 0.000 \\
$X_{1}$ & -9.767 & 1.358 & -7.192 & $0.000^{*}$ \\
$X_{2}$ & 1.758 & 1.358 & 1.295 & 0.214 \\
$X_{3}$ & -0.017 & 1.358 & -0.012 & 0.990 \\
$X_{4}$ & -1.683 & 1.358 & -1.240 & 0.233 \\
$X_{1}^{2}$ & -0.150 & 1.244 & 1.326 & 0.203 \\
$X_{2}^{2}$ & 1.650 & 1.244 & 1.326 & 0.203 \\
$X_{3}^{2}$ & 3.857 & 1.244 & 2.884 & $\left.0.011^{* *}\right)$ \\
$X_{4}{ }^{2}$ & 0.975 & 1.244 & 0.784 & 0.445 \\
$X_{1} X_{2}$ & 0.050 & 1.663 & 0.030 & 0.976 \\
$X_{1} X_{3}$ & 0.225 & 1.663 & 0.135 & 0.894 \\
$X_{1} X_{4}$ & 4.313 & 1.663 & 2.593 & $0.020^{* *}$ \\
$X_{2} X_{3}$ & 0.063 & 1.663 & 0.038 & 0.970 \\
$X_{2} X_{4}$ & -0.350 & 1.663 & -0.210 & 0.836 \\
$X_{3} X_{4}$ & -3.950 & 1.663 & -2.375 & $0.030^{* *}$ \\
\hline
\end{tabular}

Significant at $0.1 \%(<0.001)$

* Significant at $5 \%(<0.05)$

$$
\begin{aligned}
Y & =\beta_{0}+\beta_{1} X_{1}+\beta_{2} X_{2}+\beta_{3} X_{3}+\beta_{4} X_{4} \\
& +\beta_{11} X_{1}^{2}+\beta_{22} X_{2}^{2}+\beta_{33} X_{3}^{2}+\beta_{44} X_{4}^{2} \\
& +\beta_{12} X_{1} X_{2}+\beta_{13} X_{1} X_{3}+\beta_{14} X_{1} X_{4} \\
& +\beta_{23} X_{2} X_{3}+\beta_{24} X_{2} X_{4}+\beta_{34} X_{3} X_{4}(2)
\end{aligned}
$$

where $Y$ is the response, $\beta_{0}$ is constant; $\beta_{1}, \beta_{2}, \beta_{3}, \beta_{4}$ represent linear coefficients; $\beta_{11}, \beta_{22}, \beta_{33}, \beta_{44}$ are the quadratic coefficients; $\beta_{12}, \beta_{13}, \beta_{14}, \beta_{23}, \beta_{24}, \beta_{34}$ are interaction coefficients.

The correlation of the response $Y$ to coded values of variables was estimated by multiple linear regressions. The regression coefficients are presented in Table 4.

The experimental data from the central composite design was fitted with second order polynomial model by performing multiple linear regressions. The correlation between hydroxyl value of polyol and four independent variables (temperature, reaction time, molar ratio of reactant and ozone concentration) in coded unit after applying of response surface methodology can be represented by the Equation (3):

$$
\begin{aligned}
Y & =117.9-9.77 X_{1}+1.76 X_{2}-0.0167 X_{3} \\
& -1.68 X_{4}+0.15 X_{1}^{2}+1.65 X_{2}^{2}+3.59 X_{3}^{2} \\
& +0.975 X_{4}^{2}+0.05 X_{1} X_{2}+0.225 X_{1} X_{3} \\
& +4.31 X_{1} X_{4}+0.0625 X_{2} X_{3}-0.350 X_{2} X_{4} \\
& -3.95 X_{3} X_{4}
\end{aligned}
$$

The result showed that the hydroxyl value of polyol was a quadratic function of molar ratio of used cooking oil to sorbitol (significant at $\mathrm{p}<0.05$ ) and a linear function of reaction temperature (significant at $p<0.001$ ). In addition, the interaction of variables (temperature and molar ratio of reactant) has significant effect on the hydroxyl value of polyol $(p<0.05)$. It was also occurred in 


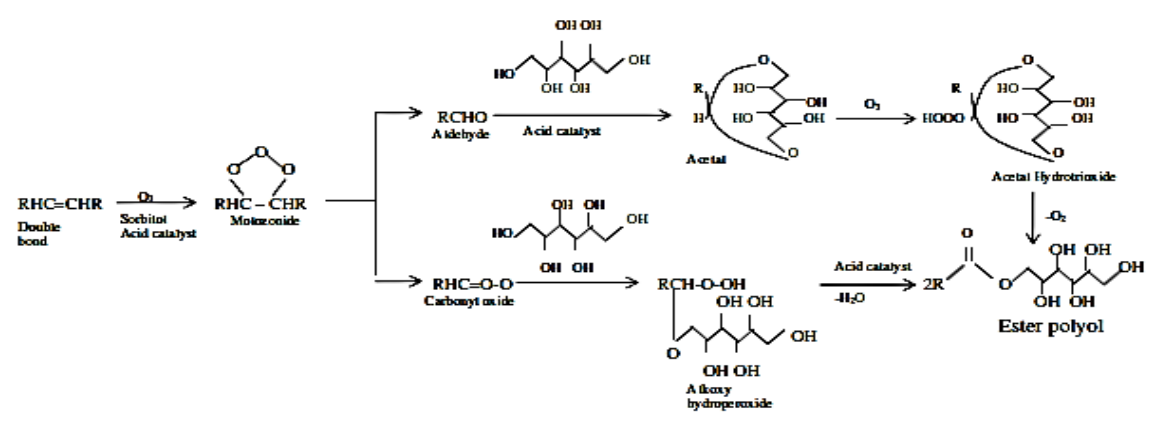

Fig 2: Ozonolysis Mechanism for Polyol Synthesis

interaction of molar ratio reactant and ozone concentration. The variable input of reaction temperature is the most significant factor for synthesis of biopolyol from used cooking oil through ozonolysis reaction (See Table 4).

\section{The Influence of Temperature on Hydroxyl Value of Polyol}

Temperature is one of the most significant factors for synthesis of polyol using ozone as a media to introduce hydroxyl groups $(p<0.001)$. The results indicated that the hydroxyl value of polyol decreased with increasing reaction temperature. At a reaction temperature of $25^{\circ} \mathrm{C}$, the hydroxyl value of polyol accounted for about $140 \mathrm{mg} \mathrm{KOH} / \mathrm{g}$ oil then dropped up to $100 \mathrm{mg} \mathrm{KOH} / \mathrm{g}$ oil while ozonolysis temperature increased to $45^{\circ} \mathrm{C}$ at 1 hour reaction time (See Figure 1). Similar result was also achieved when ozonolysis reaction was run at 5 hours (See Figure 1). This result can be explained by the fact that through the ozonolysis reaction double bonds were converted to polyol and ozone is needed as a media to introduce hydroxyl groups' source as can be seen in the reaction mechanism form as described in Figure 2 (Benecke et al. 2008).

The ozonolysis depends on the availability of ozone as a media. Higher reaction temperature reduced dissolved

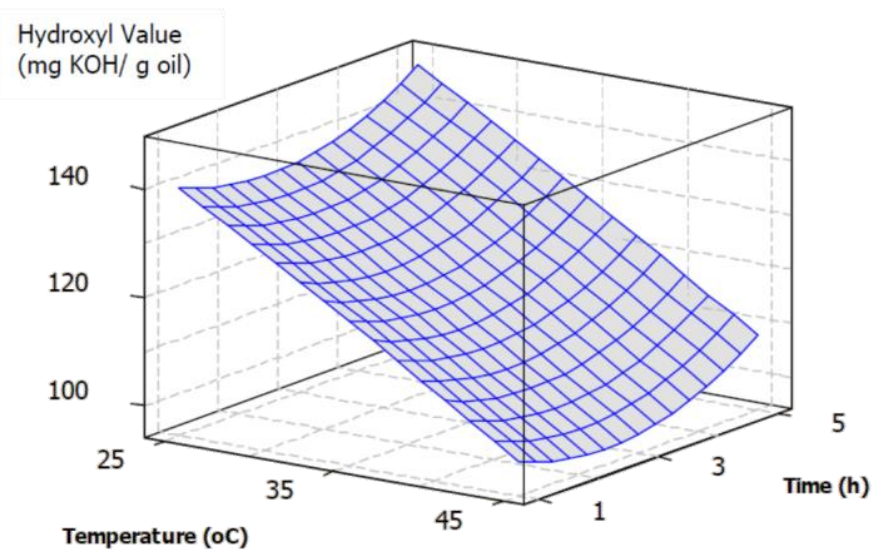

Fig 3: Temperature and Reaction Time vs Hydroxyl Value 


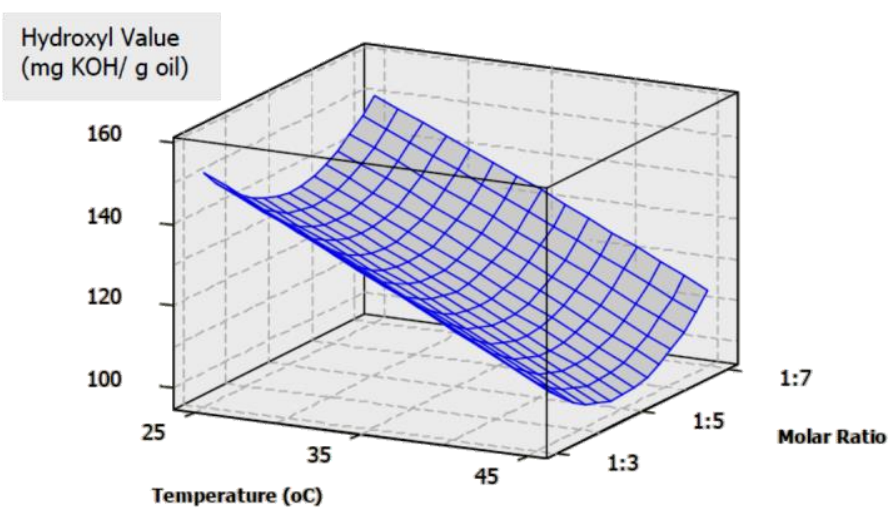

Fig 4: Temperature and Molar Ratio vs Hydroxyl Value

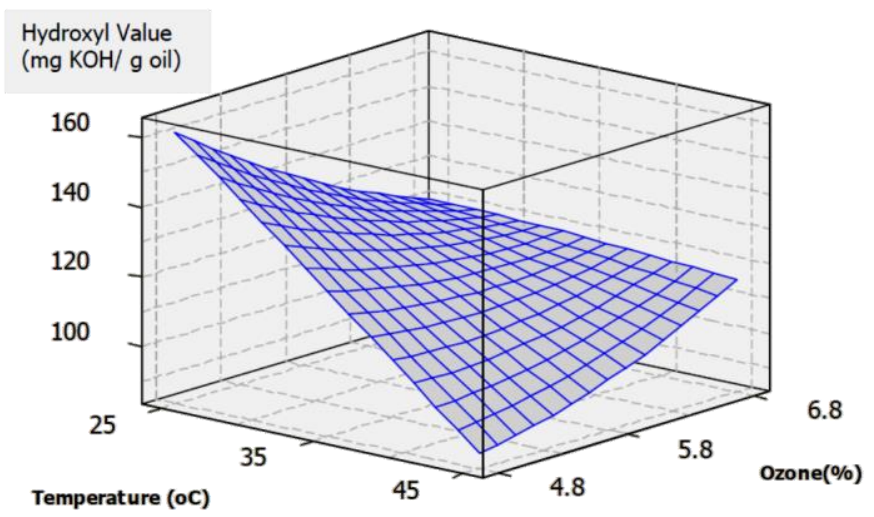

Fig 5: Temperature and Ozone Concentration vs Hydroxyl Value

ozone concentration in the oil hence it will reduce the amount of polyol product (www.ozonesolutions.com).

The result of this study also indicated the similar trend with previous result that the hydroxyl value of polyol decreased with the rise of reaction temperature at all molar ratio of reactant condition in the range of 1:3 to 1:7 (See Figure 4).

There was a significant decrease of the hydroxyl value of polyol from 160 to 85 $\mathrm{mg} \mathrm{KOH} / \mathrm{g}$ oil for higher reaction temperature at lower ozone concentration of $4.8 \%$ whereas at higher ozone concentration of $6.8 \%$, there is no significant effect of temperature on the hydroxyl value as indicated by the hydroxyl value which is relatively constant at 115 $\mathrm{mg} \mathrm{KOH} / \mathrm{g}$ oil (See Figure 5).

\section{The Influence of Reaction Time on Hydroxyl Value of Polyol}

Figure 3 showed that the hydroxyl value just slightly increased at longer reaction time either at lower or higher temperature. Hence, reaction time has no significant effect on the ozonolysis reaction to produce biopolyol. It can be described as longer reaction time will slightly increase the conversion of ozonolysis reaction hence resulted in polyol product (Levenspiel 1972). To prove hydroxyl 


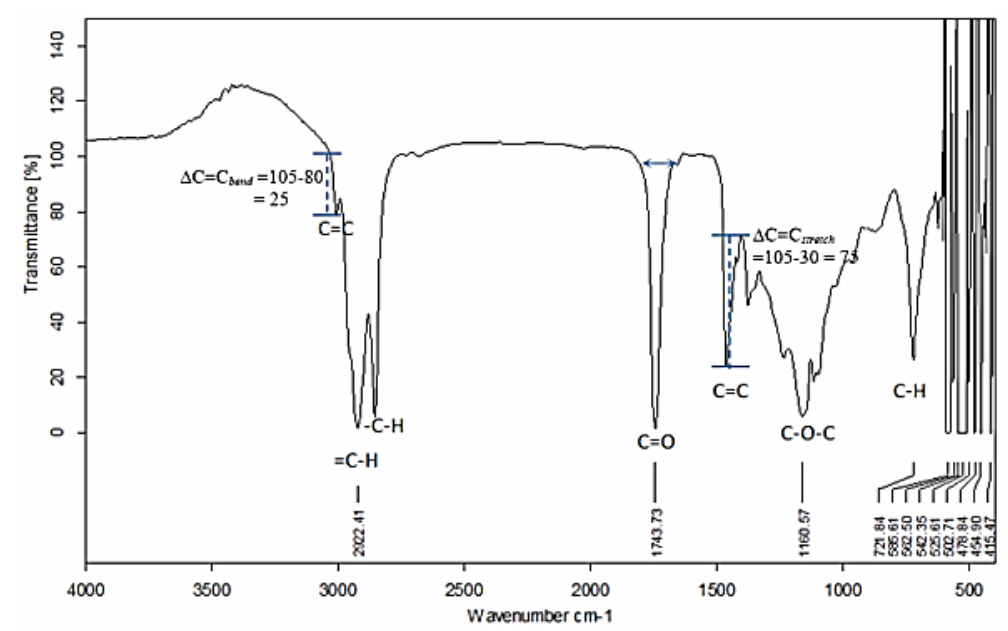

Fig 6: FTIR Spectra of Used Cooking Oil

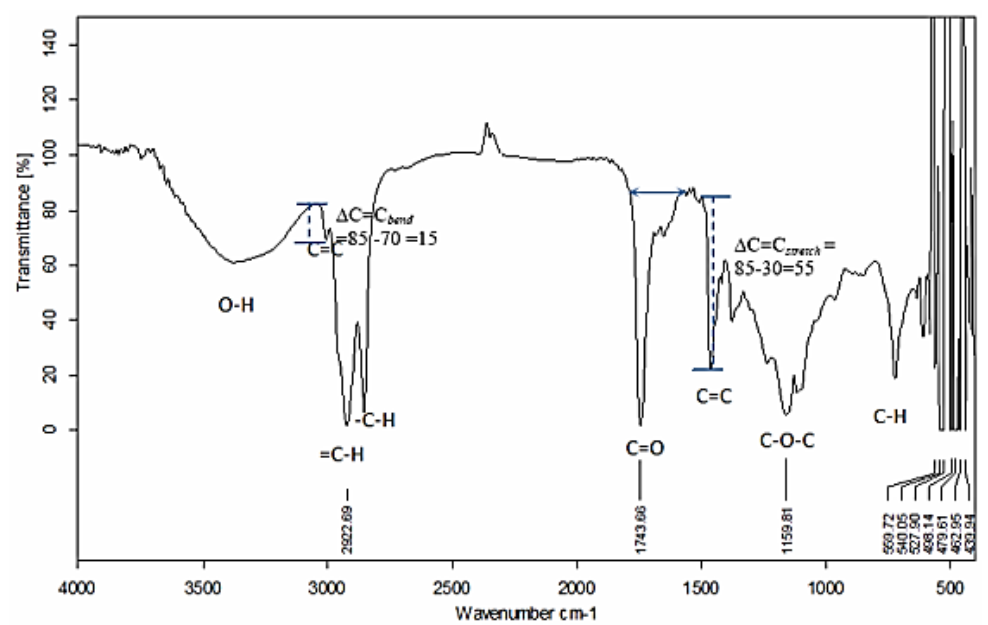

Fig 7: FTIR Spectra of Used Cooking Oil After Ozonolysis (Biopolyol)

groups are formed as a result of double bonds conversion, a FTIR analysis was carried out. Figure 6 and 7 showed the profile of FTIR analysis of used cooking oil and biopolyol. The appearance of hydroxyl groups and the decrease of double bonds in Figure 7 compare to Figure 6 showed that the conversion of double bonds to hydroxyl groups was performed.

Figure 8 showed that at $35^{\circ} \mathrm{C}$ and ozone concentration of $5.8 \%$, the hydroxyl value slightly decreased for the first 3 hours of reaction, and then it increased started after 3 hours of reaction at each molar ratio. Meanwhile at $35^{\circ} \mathrm{C}$, molar ratio of 1:5, and each ozone concentration, the hydroxyl value decreased for the 2 hours of reaction time, and then increased after 2 hours of reaction time (See Figure 9).

\section{The Influence of Molar Ratio and Ozone Concentration on Hydroxyl Value of Polyol}

As illustrated in Figure 4, the hydroxyl value of polyol slightly decreased with increasing of molar ratio, it is then reached a minimum level at molar ratio of 1:5. After that, the hydroxyl value increased with increasing molar ratio at each reaction 


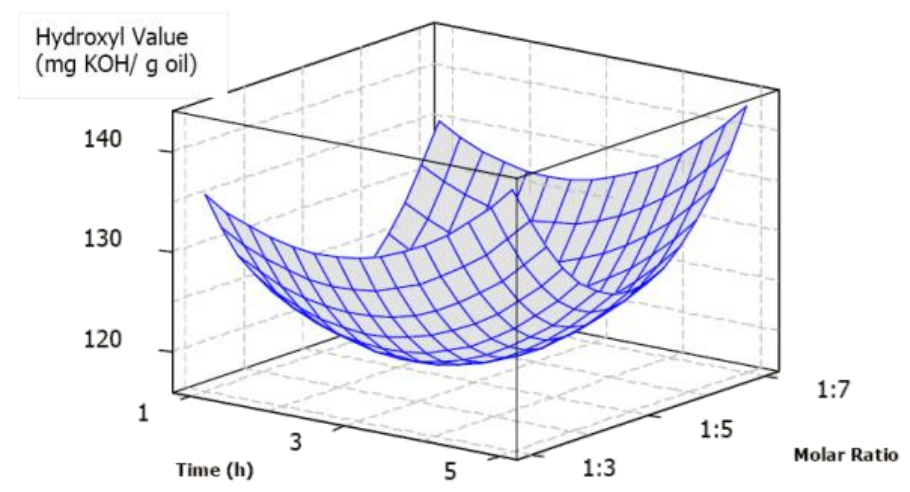

Fig 8: Reaction Time and Molar Ratio vs Hydroxyl Value

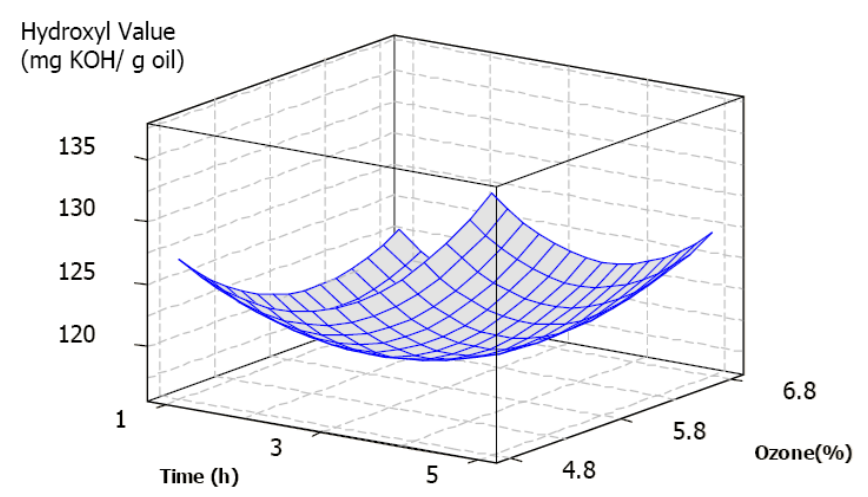

Fig 9: Reaction Time and Ozone Concentration vs Hydroxyl Value

temperature level. The experimental results at $35^{\circ} \mathrm{C}$ and reaction time of 3 hours indicated that hydroxyl value decreased from 155 to $115 \mathrm{mg} \mathrm{KOH} / \mathrm{g}$ oil with increasing ozone concentration at higher molar ratio of oil to sorbitol. The hydroxyl value increased from $122 \mathrm{mg}$ $\mathrm{KOH} / \mathrm{g}$ oil to $144 \mathrm{mg} \mathrm{KOH} \mathrm{/g}$ oil with increasing ozone concentration at lower molar ratio of oil to sorbitol. It may be explained that the solubility of ozone in oil is better at more viscous mixture, hence at lower molar ratio the hydroxyl value increased compare to that at higher molar ratio (See Figure 10).

Therefore, the ozonolysis reaction will achieve high conversion if reaction was performed at lower molar ratio of reactant with higher ozone concentration and vice versa.

\section{The Optimization of Polyol Synthesis Using Ozone}

The optimal condition for synthesis of polyol was indicated by high content of the hydroxyl value of polyol. The optimal condition to synthesis of polyol using ozone as a media is at reaction temperature of $25^{\circ} \mathrm{C}$, reaction time 5 hours, molar ratio of oil to sorbitol 1:7 and ozone concentration $4.8 \%$ with the 


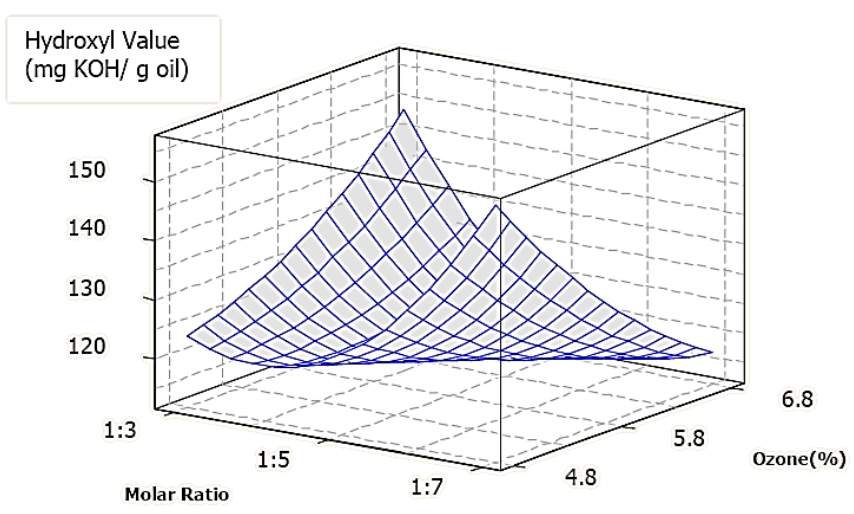

Fig 10: Molar Ratio and Ozone Concentration vs Hydroxyl Value

hydroxyl value of polyol could achieve 202 $\mathrm{mg} \mathrm{KOH} / \mathrm{g}$ oil.

\section{CONCLUSIONS}

Response surface method utilizing a full factorial central composite design was performed for four independent variables (temperature, reaction time, molar ratio of reactant and ozone concentration) to determine the optimal operating condition in the synthesis of polyol using ozone. This optimization method confirmed that RSM strategy was time saving, less complex and highly efficient. This study indicated that polyol could be produced using injection of ozone gas into a mixture of used cooking oil, sorbitol and acid catalyst and four independent variables have different effect on the hydroxyl value of polyol. Temperature has a negative effect on the hydroxyl value of polyol whereas reaction time shows a positive impact to the formation of hydroxyl groups. The second finding was high amount of hydroxyl value could be achieved if ozonolysis reaction performed at significant different level of molar ratio of reactant and ozone concentration. The optimal condition in the synthesis of polyol using ozone achieved at a temperature of $25^{\circ} \mathrm{C}$, reaction time 5 hours, molar ratio of oil to sorbitol $1: 7$ and ozone concentration of $4.8 \%$.

\section{ACKNOWLEDGEMENTS}

The authors would like to acknowledge for the financial support provided by Research Grant from Indonesian Directorate General of Higher Education.

\section{REFERENCES}

1. Baber, T.M., Gravier, D., Lira, C.T., and Narayan, R. (2005). Application of catalytic ozone chemistry for improving biodiesel product performance, Biomacromolecules, 6, 1334-1344.

2. Bailey, A.E. (1951). Industrial oil and fat products, $2^{\text {nd }}$ edn, Interscience Publisher, Inc, New York.

3. Benecke, H.P., Vijayendran, B.R., Garback, D.B., and Mitchel, K.P. (2008). Low cost and highly reactive biobased 
polyols: a co-product of the emerging biorefinery economy, Clean, 36, 694699.

4. Doddapaneni, K.K., Tatineni, R., Potumarthi, R., and Mangamoori, L.N. (2007). Optimization of media constituents through response surface methodology for improved production of alkaline proteases by serratia rubidaea, Journal of Chemical Technology and Biotechnology, 82, 721729.

5. Lligadas, G., Ronda, J.C., Galia, M., and Cadiz, V. (2006). Novel siliconcontaining polyurethanes from vegetable oils as renewable resources. Synthesis and properties, Biomacromolecules, 7, 2420-2426.

6. Montgomery, D.C. (2005). Design and analysis of experiments, $6^{\text {th }}$ edn, John Wiley \& Sons, Inc, New Jersey.

7. Ozone Solutions. (2012). Ozone solubility. Online: www.ozonesolutions.com/info/ozonesolubility.

8. Pechar, T.W., Sohn, S., Wilkes, G.L., Ghosh, S., Frazier, C.E., Fornof, A., and Long T.E. (2006). Characterization and comparison of polyurethane networks prepared using soybean-based polyols with varying hydroxyl content and their blends with petroleum-based polyols, Journal of Applied Polymer Science, 101, 1432-1443.

9. Petrovic, Z., Guo, A., and Javni, I. (2003). Process for the preparation of vegetable oil-based polyols and electroinsulating casting compounds created from vegetable oil-based polyols. United States Patent 6,573,354.

10. Tu, Y., Kiatsimkul, P., Suppes, G., and Hsieh, F. (2007). Physical properties of water-blown rigid polyurethane foams from vegetable oil-based polyols, Journal of Applied Polymer Science, 114, 2577-2583.

11. Wang, D., Zhang, G., Zhang, Y., Gao, Y., Zhao, Y., Zhou, C., Zhang, Q., and Wang, X. (2009). Synthesis, characterization, and properties of novel polyetherester polyols and developed polyurethanes, Journal of Applied Polymer Science, 103, 417-424.

12. Wang, J., and Wan, W. (2008). Optimization of fermentative hydrogen production process by response surface methodology, International Journal of Hydrogen Energy, 33, 69766984. 